\title{
Sarkoidozun Yaygınlığının Değerlendirilmesinde FDG PET/ BT Bulguları ile Nötrofil/Lenfosit Oranının Karşılaştırılması
}

\author{
Comparison of FDG PET/BT Findings and Neutrophil/ \\ Lymphocyte Ratio in the Evaluation of the Extent of Sarcoidosis
}

\author{
Hasan Önner ${ }^{1}$, Mustafa Erol $^{1}$
}

${ }^{1}$ Sağlık Bilimleri Üniversitesi, Konya Eğitim Araştırma Hastanesi, Nükleer Tıp Kliniği, Konya, Turkey

Yazışma Adresi: Hasan Önner, Sağlık Bilimleri Üniversitesi, Konya Eğitim Araştırma Hastanesi, Nükleer Tıp Kliniği, Konya, Turkey e-posta: hasanonner1988@hotmail.com

Geliş Tarihi/Received: 1 Ocak 2020 Kabul Tarihi/Accepted: 17 Ağustos 2020

\begin{abstract}
Öz
Amaç: Sarkoidoz tedavisinin kararında, klinik ve radyolojik bulgular ile takipte solunum fonksiyon testindeki bozulmaya bakılmakta olup, tedavi yönetiminde farklı tetkiklere ihtiyaç duyulmaktadır. Flor-18 florodeoksiglukoz (18F-FDG) pozitron emisyon tomografisi/bilgisayarlı tomografi (PET/BT) hastalığın yaygınlığı hakkında bilgi verirken; nötrofil/lenfosit oranı (NLO) inflamasyon için iyi bir prognostik belirteç olarak bildirilmektedir. Bu çalışmada, sarkoidozun 18F-FDG PET/BT bulguları ile NLO ve diğer klinik bulgular arasındaki ilişkiyi. Hastalar ve Yöntem: Ocak 2017 - Aralık 2019 tarihleri arasında Kliniğimizde, 18F-FDG PET/BT tetkiki sarkoidoz tanısı alan hastaların verileri NLO ve retrospektif olarak tarandı. Yaş, cinsiyet, sigara öyküsü, semptomlar, ekstratorasik tutulum varlığı ile 18F-FDG PET/BT bulguları karşılaştırıldı.

Bulgular: Çalışmaya 41 hasta dahil edildi. NLO ile tüm vücut toplam lezyon glikolizi (TLG) arasında güçlü, tüm vücut metabolik aktif inflamatuar alan (MAIA) arasında orta düzeyde anlamlı korelasyon saptandı (Sırasıyla $r$ değerleri: 0.852 , 0.660; her ikisi içinde $p$ değeri: $<0.001$ ). Torasik tutulumu olan hasta grubu ile ekstratorasik tutulumu olan hasta grubu arasında MAIA, TLG ve NLO değerleri ile anlamlı farklılık saptandı ( $p$ değerleri sırasıyla: $0.002,0.001$ ve 0.003 ). Semptomlara göre yapılan sınıflamada gruplar arasında STDmaks, MAIA, TLG ve NLO değerleri ile anlamlı farklılık saptanmadı. Yaşı grupta anlamlı olarak daha yüksek MAIA ve TLG medyan değerleri bulundu (sırasıyla p değerleri: 0,037 ve 0,040). Cinsiyet grupları arasında STDmaks, MAIA, TLG ve NLO değerleri ile anlamlı farklılık saptanmadı.

Sonuç: Sarkoidozda prognostik bir gösterge olarak kabul edilen NLO ile tüm vücutta hastalığın yaygınlığın gösteren 18F-FDG PET/BT bulguları arasında saptadığımız yakın ilişki, tedavi yönetiminde klinisyene öneml bilgiler verebilir.
\end{abstract}

Anahtar Kelimeler: Sarkoidoz; F-18 florodeoksiglukoz pozitron emisyon tomografisi/bilgisayarlı tomografi; nötrofil/lenfosit oranı; metabolik aktif inflamatuar alan; toplam lezyon glikolizi.

\begin{abstract}
Aim: The decision of treatment in sarcoidosis is made based on clinical and radiological findings and changes in pulmonary function test findings during follow-up, and more useful tools are needed. F-18 fluorodeoxyglucose (18F-FDG) positron required important tomography/computed tomography (PET/CT) contains information about the extent of sarcoidosis. Neutrophil/lymphocyte ratio (NLR) opens as a prognostic marker for inflammation. This study evaluated the relationship between the 18F-FDG PET/CT findings of sarcoidosis and NLR and other clinical findings.

Patients and Methods: The data of patients who were diagnosed with sarcoidosis after 18F-FDG PET/ CT scan in our clinic between January 2017 and December 2019 were reviewed retrospectively. Patients' age, gender, NLR values, smoking status, extrathoracic involvement and symptoms, and 18F-FDG PET/CT findings were compared.

Results: This study consisted of 41 patients. There were strong correlations between NLR and whole body total lesion glycolysis (TLG), and moderate correlation between MAIA ( $r$ values: $0.852,0.660$, both of them $p$ value: $<0.001$, respectively). There were significant differences between thoracic involvement and extrathoracic involvement with MAIA, TLG and NLR values ( $p$ values,: $0.002,0.001$ and, 0.003 , respectively). According to the symptoms of the patients, there was no significant difference between the groups with SUVmax, MAIA, TLG and NLR values. Median values were found to be significantly higher in the elderly group ( $p$ values: 0.037 and 0.040 , respectively). Were no significant differences in both PET/CT parameters and NLR values.

Conclusion: The close relationship between the NLR value, which is accepted as a prognostic indicator in sarcoidosis, and the 18F-FDG PET/CT findings which show the involvement of the disease in the whole body, may provide the clinicians with significant benefits in treatment management.
\end{abstract}

Key words: Sarcoidosis, F-18 fluorodeoxyglucose positron emission tomography/computed tomography, neutrophil/lymphocyte ratio, metabolically active inflammatory area, total lesion glycolysis.

Atıf yapmak için: Önner $H$, Erol $M$. Sarkoidozun Yaygınlığının Değerlendirilmesinde FDG PET/BT Bulguları ile Nötrofil/Lenfosit Oranının Karşılaştırılması. Selcuk Med J 2021;37(2): 101-105
Açıklama: Yazarların hiçbiri, bu makalede bahsedilen herhangi bir ürün, aygıt veya ilaç ile ilgili maddi çıkar ilişkisine sahip değildir. Araştırma, herhangi bir dış organizasyon tarafından desteklenmedi. Yazarlar çalışmanın birincil verilerine tam erişim izni vermek ve derginin talep ettiği takdirde verileri incelemesine izin vermeyi kabul etmektedirler. 


\section{GíRiş}

Sarkoidoz etyolojisi net olarak bilinmeyen özellikle akciğerleri tutan ilerleyici sistemik granülamatöz bir hastalıktır(1). Kadınlarda ve 20-40 yaş aralığında daha sıkgörülmektedir. Dünyada coğrafi bölgelere göre yıllık insidansı 100.000 'de 0.1 ila 81 arasında değişmekle birlikte; ülkemizde yıllık insidansı 100.000 'de 4 olarak bildirilmektedir (2). Hastalığın tanısı, klinik tablo ve radyolojik görüntülemeler eşliğinde dokuda non-kazeifiye granülamatöz reaksiyon bulgusunun gösterilmesi ve diğer infeksiyöz/inflamatuar ve malign proçeslerin dışlanması ile konulmaktadır (3). Güncel pratikte tedaviye başlama kararı, klinik ve radyolojik bulgular ile solunum fonksiyonlarındaki değişikliklerin birlikte yorumlanmasına dayanmaktadır (4). Ancak bu yaklaşım akciğerdeki inflamasyonun şiddetini ve ilerleyişini tahmin etmede yetersiz kalmaktadır (5).

Aktif hastalıkta bronkoalveoler lavaj sıvısında anjiyotensin dönüştürücü enzim (ACE), adenosin deaminaz (ADA), total lgE ve neopterin gibi bazı parametrelerin arttığını bildiren çalışmalar bulunmaktadır $(6,7)$. Kolay ve ucuz bir test olan tam kan sayımından elde edilen nötrofil/lenfosit oranının (NLO) sarkoidozda inflamasyonun bir göstergesi olarak kullanılabileceği belirtilmektedir $(8,9)$. Glikoz analoğu olan 18F-FDG, hücre zarı glikoz taşıyıcıları yoluyla hücreler tarafından alınır ve hücrenin içinde hekzokinaz ile fosforile edilerek hapsolur. İnflamasyondan sorumlu hücrelerin, özellikle nötrofil ve monosit/makrofaj ailesinin yüksek seviyelerde glikoz taşıyıcılarını eksprese ettiği ve hekzokinaz enzim aktivitelerinin yüksek olduğu bilinmektedir (10, 11). Avrupa ve Amerika kılavuzları, vücutta 18F-FDG biodağılımını gösteren F-18 florodeoksiglukoz (18F-FDG) pozitron emisyon tomografisi/bilgisayarlı tomografi (PET/BT) tetkikinin, sarkoidozda hastalığın şiddetini belirlemede, ilerleyişini tahmin etmede ve tedavisinin yönetiminde kullanımını önermektedir (12).

Bildiğimiz kadarıyla, literatürde 18F-FDG PET/ BT bulguları ile nötrofil-lenfosit oranını (NLO) karşılaştıran bir çalışma bulunmamaktadır. Bu yüzden çalışmamızda, sarkoidoz hastalarında tam kan sayımından elde edilen NLO ile 18F-FDG PET/ BT parametreleri [maksimum standart tutulum değeri (STDmaks), metabolik aktif inflamatuar alanı (MAì) ve toplam lezyon glikolizi (TLG)] karşılaştırılarak incelendi.

\section{HASTALAR VE YÖNTEM}

Ocak 2017 - Aralık 2019 tarihleri arasında kliniğimizde 18F-FDG PET/BT taraması yapılan ve tetkik sonrası uluslararası kriterlere (13) göre sarkoidoz tanısı alan (tetkik ile tanı arası geçen sürenin medyan değeri: 20 gün) hastaların, tam kan sayımı parametreleri ve 18F-FDG PET/BT bulguları retrospektif olarak değerlendirildi. Tam kan sayımları ile 18F-FDG PET/BT tetkiki arası geçen süre en fazla 10 gündü. NLO, mutlak nötrofil sayısının mutlak lenfosit sayısına bölünmesiyle hesaplandı. Hastalar sadece torasik tutulumu olanlar ve ilave ekstratorasik tutulumu olanlar olarak iki grubu ayrıldı. 18F-FDG PET/BT ile nörosarkoidoz ve kardiyak sarkoidoz değerlendirilmesi için özel çekim protokolü gerektiği için bu alanlar çalışmada değerlendirilmedi. KTO Karatay Üniversitesi Tıp Fakültesinden Çalışmamız için yerel etik kurul onayı alınmıştır (2020/48).

\section{F-FDG PET/BT Görüntüleme Protokolü}

Hastalara 24 saatlik karbonhidrattan fakir diyetinden ardından 18F-FDG PET/BT tetkiki yapıldı. 18F-FDG enjeksiyonu öncesi hastaların kan şekeri $200 \mathrm{mg} / \mathrm{dL}$ 'nin altındaydı. 18F-FDG intravenöz olarak enjekte edildikten $(3.7 \mathrm{MBq} / \mathrm{Kg}) 60$ dakika sonra kafatası tabanından üst uyluğa kadar Siemens 16 Truepoint PET/BT tarayıcısı (Siemens AG Medical Solutions, Erlangen, Almanya) ile görüntüleme yapıldı. Görüntüler transaksiyal, koronal ve sagittal düzlem kesitleri farklı renk ve kontrastlı pencerelerde değerlendirildi. Görüntü işleme için Syngo TrueD VD20A yazılımını kullanıldı. 18F-FDG PET/BT tetkiki iki nükleer tıp uzmanı tarafından birlikte ortak kararlar ile yorumlandı.

\section{PET/BT Parametrelerinin Hesaplanması}

18F-FDG PET/BT görüntülerindeki patolojik düzeyde 18F-FDG tutulumu gösteren alanlar için ilgi alanları çizildi. İlgi alanı içerisindeki aktivitenin ( $\mathrm{mCi} /$ $\mathrm{mL}$ ) enjekte edilen doza $(\mathrm{mCi} / \mathrm{kg})$ bölünmesi ile STD değeri elde edildi. PET görüntülerinden hesaplanan STD değeri, dokuların 18F-FDG tutulumunu değerlendirmede kullanılan yarı kantitatif bir parametredir. Klinik uygulamada STDmaks en yaygın kullanılan STD tipi olup çizilen ilgi alanı içerisindeki maksimum 18F-FDG tutulumunu göstermektedir. Seçilen ilgi alanı içerisindeki lezyonun metabolik yükünü ise MAIA değeri yansıtmaktadır. Bu alandaki aktivitenin STDmaks'ının \%42'si eşik değer alınarak yazılım (Syngo TrueD VD20A) tarafından hesaplanmaktadır. TLG ise hem metabolik aktiviteyi hem de glikolitik aktiviteyi birlikte yansıtmakta olup, aşağıda formülüze edildiği gibi MTV ile STDortalama değerlerinin çarpılması ile hesaplanmaktadır.

[TLG = STDortalama X MAIA $\left(\mathrm{cm}^{3}\right)$ ] 
Patolojik düzeyde 18F-FDG tutulumu gösteren alanlarının MAIA ve TLG değerleri toplanarak hastalığın tüm vücuttaki toplam inflamatuar yükü hesaplandı. Patolojik düzeyde 18F-FDG tutulum gösteren alanlar torasik ve ekstraktorasik olarak iki gruba ayrıldı.

\section{İstatistiksel Analiz}

Verilerin dağılımlarının normalliği KolmogorovSmirnov testi ile kontrol edildi. Veriler normal dağılım göstermediği medyan değerleri kullanıldı. Kategorik değişkenler n (\%) olarak sunuldu. Gruplar arasındaki karşılaştırmalar Mann-Whitney-U veya Kruskal-Wallis testleri kullanılarak yapıldı. Veriler Windows için SPSS 21.0 kullanılarak analiz edildi (SPSS Inc, Chicago, IL, ABD). PET/BT parametreleri ve NLO normal dağılımı göstermediği için Spearman korelasyon analizi ile değerlendirildi. $p<0,05$ değerleri istatistiksel olarak anlamlı kabul edildi.

\section{BULGULAR}

Çalışmaya toplam 41 hasta dahil edildi. Hastaların 11'i erkek (\%26.83), 30'u kadın (\%73.17) olmak üzere

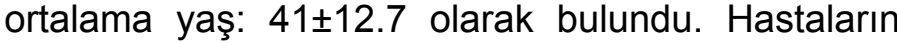
16 'sı (\%39.02) halen sigara içmekteydi veya daha önceleri sigara içmişti. Hastaların 24'ünde (\%58.54) öksürük, 19'unda (\%46.34) halsizlik ve $15^{\prime}$ 'inde (\%36.59) nefes darlığı şikayetleri mevcuttu. On yedi (\%41.46) hastada torasik alanlara ilave olarak ektratorasik alanlarda tutulum bulgusu mevcuttu. Hastaların demografik verileri tablo 1 'de sunulmuştur. Hastaların önemli bir kısmında non-kazeifiye granülamatöz reaksiyon bulgusu endobronşiyal ultrasonografi ile mediastinal lenf nodu örneklemesi (36 hastada) ile bulunurken; diğer hastalarda bu bulgu

Table 1. Hastaların demografik bulguları

\begin{tabular}{lll}
\hline Yaş & & $41 \pm 12.7$ \\
& 65 yaş altı & $30(\% 73.17)$ \\
Cinsiyet & 65 yaş üstü & $11(\% 26.83)$ \\
& Erkek & $11(\% 26.83)$ \\
İlave ekstratorasik & Kadın & $30(\% 73.17)$ \\
tutulum & Var & $17(\% 41.46)$ \\
Sigara & Yok & $24(\% 58.54)$ \\
& Var & $16(\% 39.02)$ \\
Şikayet & Yok & $25(\% 60.98)$ \\
& Öksürük & $24(\% 58.54)$ \\
& Nefes darlığı & $19(\% 46.34)$ \\
& Halsizlik & $15(\% 36.59)$ \\
\hline
\end{tabular}

servikal ( 2 hastada) ve aksiller ( 1 hastada) lenf nodu örneklemeleri ya da transtorasik akciğer biyopsisi ile akciğer parankiminden (2 hastada) alınan örnekleme ile saptandı.

Çalışmaya dahil edilen hastaların tutulum alanlarında medyan STDmaks değeri: 13.6, medyan MAIA değeri: 88.10 ve medyan TLG değeri: 474.30 olarak hesaplanırken; NLO'nın medyan değeri: 3.34 olarak bulundu. PET/BT bulguları ve NLO ile arasındaki korelasyon incelendiğinde; TLG ve NLO arasında güçlü, MAIIA ve NLO arasında orta düzeyde anlamlı korelasyon saptandı (Sırasıyla $r$ değerleri: 0.852, 0.660; her iki korelasyon içinde p değeri: <0.001 olarak bulundu.). Tüm hastalarda torasik alanlarda tutulum mevcuttu. Hastalar, sadece torasik tutulumu olanlar [24 (\%58.54)] ve ilave ekstratorasik tutulumu olanlar [17 (\%41.46)] olarak iki grubu ayrıldığında; MAIA, TLG ve NLO değerleri ile iki grup arasında anlamlı farklılık saptandı (Sırasıyla $p$ değerleri: $0,002,0,001$ ve 0,003). Hastalar semptomlarına göre gruplandırıldığında ise gruplar arasında STDmaks, MAIA, TLG ve NLO değerleri ile anlamlı farklılık saptanmadı. Altmış-beş yaş altı genç grup ve 65 yaş üstü yaşlı grup olarak yapılan sınıflamada yaşlı grupta anlamlı olarak daha yüksek MAİA ve TLG medyan değerleri bulundu (sırasıyla $p$ değerleri: 0,037 ve $0,040)$. Cinsiyete göre yapılan sınıflamada hem PET/ BT parametreleri ile hem de NLO değeri ile anlamlı farklılık saptanmadı.

\section{TARTIŞMA}

Sarkoidoz hastalarında spontan remisyon sık olduğu için çoğu hastaya tedavi yapılmamaktadır. Ancak hangi hastanın tedavi edileceği halen tartışmalı olmakla birlikte semptomatik, ilerleyici veya başlangıçtan itibaren agresif klinik bulguları olan hastalar tedavi edilmektedir (14). Tedavi yönetiminde klinisyene kılavuzluk edecek farklı klinik, laboratuvar ve görüntüleme yöntemlerine ihtiyaç duyulmaktadır.

Nötrofiller inflamasyonun öncü hücreleri olup inflamatuar süreçlerin ana tetikleyicileridir. Tersine lenfositler doku hasarı yerine spesifik bağışıklıkta rol oynamaktadırlar. İnflamatuar süreçlerde gözlenen lenfositopeninin nedeni artan stres ve yüksek plazma kortizol seviyeleri olabilir. Bu faktörlere ilave olarak; sarkoidozun tutulum alanlarında yoğun olarak CD4+ T-lenfositler toplanmakta ve bu alanlarda CD4+/CD8+ hücre oranı oldukça yüksek saptanmaktadır. Olguların \%90'ından fazlasında akciğer tutulumu gözlenmekte olup özellikle alveol boşlukları ve interstisyumda lenfosit birikimi olmaktadır. Bu yüzden bronkoalveoler 
lavajda CD4+/CD8+ oranı oldukça yüksek seviyede saptanmaktadır. Bu bulgular lenfosit göçü olarak değerlendirilmekte olup, bronkoalveoler lavajda lenfositoz, periferik kanda ise lenfopeni tablosunun nedeni olarak belirtilmektedir (15). Periferik kanda lenfopenin diğer nedenleri arasında, inflamasyon sonucu salgılanan sitokinlerin lenfogenezisi baskılaması veya diğer mekanizmalar nedeniyle artan periferik yıkım sayılmaktadır (16). Bu hematolojik parametrelerin her ikisindeki değişiklikleri temsil eden NLO, kanserlerde ve içlerinde sarkoidozunda olduğu inflamatuar hastalıklarda önemli bir prognostik gösterge olarak kabul edilmektedir (8, 17-20).

Inflamatuar süreçlerde, nötrofiller, aktif makrofajlar ve lenfositler gibi inflamatuar hücrelerin 18F-FDG alımı artmaktadır. Bu özellik 18F-FDG'nin inflamatuar hastalıkların yaygınlığının değerlendirilmesinde ve tedavi yönetiminde önemli bir avantaj olarak görülmektedir (21-23). Çalışmamızda, NLO ile tüm vücutta metabolik aktif inflamatuar yükü gösteren 18F-FDG PET/BT bulguları arasında yakın ilişki saptandı.Ayrıca ilave ekstratorasik tutulumu olan hasta grubunda daha yüksek MAIA, TLG ve NLO medyan değerlerinin saptanması bu parametrelerin hastalığın yaygınlığı ile ilişkili olduğunu göstermektedir. Mostard et al. (24) hastalığın akciğer tutulumunun şiddetini ve yaygınlığını yüksek rezolüsyonlu akciğer tomografisi (HRCT) ve akciğer fonksiyon testi ile belirledikleri çalışmalarında HRCT ve akciğer fonksiyon testi bulgularının 18F-FDG tutulumu ile ilişkili olduğunu bildirmişlerdir. Başka bir çalışmada, 18F-FDG PET/ BT ile akciğerde diffüz parankimal tutulumu saptanan hastaların tedavi edilmediği takdirde solunum fonksiyon testlerinin kötüleşeceği belirtilmiştir (25). Ayrıca akciğerdeki 18F-FDG tutulum alanlarının hastalığın histopatolojik bulguları ile korele olduğu ve yüksek doz steroid tedavisinden sonra kontrol PET/BT çalışmasında tedavi yanıtı olarak bu tutulum alanlarının azaldığı bildirilmiştir (26). Sarkoidozda hastalığın yaygınlığını değerlendirmede, diğer bir nükleer tıp görüntüleme yöntemi olan galyum-67 sintigrafisi ile 18F-FDG PET/BT'yi karşılaştıran bir çalışmada; 18F-FDG PET/BT ile ekstratorasik tutulum alanlarının daha iyi değerlendirildiği rapor edilmiştir (27).

Bildiğimiz kadarıyla, literatürde sarkoidozun 18F-FDG PET/BT bulguları ile NLO'nı karşılaştıran bir çalışma bulunmamaktadır. Bununla birlikte, hastalığın akciğerdeki yaygınlığını değerlendirmede klinik pratikte sıklıkla kullanılan HRCT bulguları ile NLO'nı karşılaştıran bir çalışmada NLO'nın akciğer sarkoidozunun radyolojik bulgularını ön görebileceği sonucuna varılmıştır (17). Çalışmamızın kısıtlamaları, tek merkez deneyiminin olması, kısıtlı hasta sayısı ve çalışmanın retrospektif karakteri olarak sıralanabilir. Bir diğer sınırlama ise uygun değerlendirme için özel protokol gerektiren nörosarkoidoz ve kardiyak sarkoidoz tutulum alanlarının bulgulara ilave edilemeyişidir. Ayrıca 18F-FDG PET/BT'de patolojik olarak tanımlanan her alan için histopatolojik doğrulama yapılamamıştır. Bulgularımızı destekleyecek çok merkezli ve prospektif çalışmalara intiyaç bulunmaktadır.

\section{SONUÇ}

Çalışmamızda sarkoidozun 18F-FDG PET/BT bulguları ile inflamatuar hastalıklarda prognostik gösterge olarak belirtilen NLO arasında yakın ilişki saptadık. Ayrıca ekstratorasik tutulumu olan olgularda daha yüksek NLO ile MAİA ve TLG değerleri mevcuttu. Bulgularımız, bu göstergelerin hastalığın yaygınlığı hakkında klinisyene önemli bilgiler vereceğini ve tedavi yönetiminde faydalı olacağını düşündürmektedir.

Çıkar Çatışması: Çalışmada herhangi bir çıkar çatışması yoktur.

Finansal Çıkar Çatışması: Çalışmada herhangi bir finansal çıkar çatışması yoktur.

Yazışma Adresi: Hasan Önner, Sağlık Bilimleri Üniversitesi, Konya Eğitim Araştırma Hastanesi, Nükleer Tıp Kliniği, Konya, Turkey

Phone: +905375401092

E-mail: hasanonner_1988@hotmail.com

\section{KAYNAKLAR}

1. Hutchinson J. Statement on sarcoidosis. Joint Statement of the American Thoracic Society (ATS), the European Respiratory Society (ERS) and the World Association of Sarcoidosis and Other Granulomatous Disorders (WASOG) adopted by the ATS Board of Directors and by the ER. Am J Respir Crit Care Med 1999;160(736):55.

2. Musellim B, Kumbasar O, Ongen G, et al. Epidemiological features of Turkish patients with sarcoidosis. Respir Med 2009;103(6):907-12.

3. Soto-Gomez N, Peters JI, Nambiar AM. Diagnosis and management of sarcoidosis. Am Fam Physician 2016;93(10):840-8.

4. Spagnolo P, Rossi G, Trisolini R, et al. Pulmonary sarcoidosis. Lancet Respir Med 2018;6(5):389-402.

5. Papiris SA, Manali ED, Pianou NK, et al. 18F-FDG PET/CT in pulmonary sarcoidosis: Quantifying inflammation by the TLG index. Expert Rev Respir Med 2020;14(1):103-10.

6. Wetzel E, Müller-Quernheim J, Lorenz J. Serum adenosine deaminase as a parameter for activity in sarcoidosis. Pneumologie 1999;53(7):323-8.

7. Gungor S, Ozseker F, Yalcinsoy M, et al. Conventional markers in determination of activity of sarcoidosis. Int 
Immunopharmacol 2015;25(1):174-9.

8. Gungor S, Akturk U, Yalcinsoy M, et al. What is the neutrophil/ lymphocyte ratio in sarcoidosis? Bratisl Lek Listy 2016;1525.

9. Iliaz S, Iliaz R, Ortakoylu G, et al. Value of neutrophil/ lymphocyte ratio in the differential diagnosis of sarcoidosis and tuberculosis. Ann Thorac Med 2014;9(4):232.

10. Kubota R, Yamada S, Kubota K, et al. Intratumoral distribution of fluorine-18-fluorodeoxyglucose in vivo: High accumulation in macrophages and granulation tissues studied by microautoradiography. J Nucl Med 1992;33(11):1972-80.

11. Mochizuki T, Tsukamoto E, Kuge $Y$, et al. FDG uptake and glucose transporter subtype expressions in experimental tumor and inflammation models. J Nucl Med 2001;42(10):1551-5.

12. Jamar F, Buscombe J, Chiti A, et al. EANM/SNMMI guideline for 18F-FDG use in inflammation and infection. $J$ Nucl Med 2013;54(4):647-58.

13. Hunninghake $G$, Costabel $U$, Ando $M$, et al. ATS/ERS/ WASOG statement on sarcoidosis. American Thoracic Society/European Respiratory Society/World Association of Sarcoidosis and other Granulomatous Disorders. Sarcoidosis Vasc Diffuse Lung Dis 1999;16(2):149.

14. Judson MA. Sarcoidosis: Clinical presentation, diagnosis, and approach to treatment. Am J Med Sci 2008;335(1):2633.

15. Agostini C, Semenzato G, editors. Cytokines in sarcoidosis. Semin Respir Infect 1998;13(3):184-96.

16. Sweiss NJ, Salloum R, Ghandi S, et al. Significant CD4, CD8, and CD19 lymphopenia in peripheral blood of sarcoidosis patients correlates with severe disease manifestations. PLoS One 2010;5(2):e9088.

17. Ocal N, Dogan D, Ocal R, et al. Effects of radiological extent on neutrophil/lymphocyte ratio in pulmonary sarcoidosis. Eur Rev Med Pharmacol Sci 2016;20(4):709-14.

18. Yalnız E, Ucsular F, Karadeniz G, et al. Predictive value of neutrophil-to-lymphocyte ratio (NLR) and platelet-tolymphocyte ratio (PLR) in patients with sarcoidosis. Eur Respiratory Soc 2018;52: PA3007.
19. Cedres S, Torrejon D, Martinez A, et al. Neutrophil to lymphocyte ratio (NLR) as an indicator of poor prognosis in stage IV non-small cell lung cancer. Clin Transl Oncol 2012;14(11):864-9.

20. Guthrie GJ, Charles KA, Roxburgh CS, et al. The systemic inflammation-based neutrophil-lymphocyte ratio: Experience in patients with cancer. Crit Rev Oncol Hematol 2013;88(1):218-30.

21. Kaira $\mathrm{K}$, Ishizuka $\mathrm{T}$, Yanagitani $\mathrm{N}$, et al. Value of FDG positron emission tomography in monitoring the effects of therapy in progressive pulmonary sarcoidosis. Clin Nucl Med 2007;32(2):114-6.

22. Nguyen BD. F-18 FDG PET imaging of disseminated sarcoidosis. Clin Nucl Med 2007;32(1):53-4.

23. Alavi $A$, Buchpiguel CA, Loessner $A$. Is there a role for FDG $P E T$ imaging in the management of patients with sarcoidosis? Soc Nuclear Med;1994.

24. Mostard RL, Verschakelen JA, van Kroonenburgh MJ, et al. Severity of pulmonary involvement and 18F-FDG PET activity in sarcoidosis. Respir Med 2013;107(3):439-47.

25. Keijsers R, Verzijlbergen E, Van Den Bosch J, et al. 18F-FDG PET as a predictor of pulmonary function in sarcoidosis. Sarcoidosis Vasc Diffuse Lung Dis 2011;28(2):123-9.

26. Brudin LH, Valind S-O, Rhodes CG, et al. Fluorine-18 deoxyglucose uptake in sarcoidosis measured with positron emission tomography. Eur J Nucl Med Mol Imaging 1994;21(4):297-305.

27. Nishiyama Y, Yamamoto Y, Fukunaga K, et al. Comparative evaluation of $18 \mathrm{~F}-\mathrm{FDG}$ PET and $67 \mathrm{Ga}$ scintigraphy in patients with sarcoidosis. J Nucl Med 2006;47(10):1571-6. 